\title{
Desemprego, informalidade e precariedade: a situação do mercado de trabalho no Brasil pós-1990
}

Geórgia Patricia Guimarāes dos Santos *

Resumo: Considerando o desemprego tanto um fenômeno inerente ao processo de acumulação capitalista como uma das consequiências das opçóes políticas governamentais, este artigo pretende discorrer sobre o papel do desemprego na definição das atuais estratégias de avanço do capitalismo, bem como refletir sobre o processo de desestruturação do mercado de trabalho e sua pequena inflexão nos anos mais recentes.

Palavras-chaves: mercado de trabalho, desemprego, informalidade.

\section{Unemployment, informality and precariousness: the labor market situation in Brazil after 1990}

Abstract: Considering unemployment as both an intrinsic phenomenon in the process of capitalist accumulation and one of the consequences of governments' political options, this article brings a discussion about the role of unemployment in the definition of the recent strategies of capitalist development, as well as a reflection about the process of structuring the labor market and its slight inflection in the latest years.

Key words: unemployment; informality; precariousness; labor market.

Introdução

[...] O que mais me impressionou em Enrico e sua geração foi ver como o tempo era linear em suas vidas: ano após ano trabathando em empregos que raras vezes variavam de um dia para o outro. E, nessa linha de tempo, a conquista era cumulativa: toda semana, Enrico e Flávia conferiam o aumento de suas poupanças, mediam a vida doméstica pelas várias melhoriase acréscimos que haviam feito na casa de fazenda. Finalmente, o tempo que viviam era previsível. As convulsôes da Grande Depressão e da Segunda Guerra Mundial haviam se esfumado, os sindicatos protegiam seus empregos; embora tivesse apenas

* Doutoranda em Ciências Sociais na Universidade Estadual de Campinas (Unicamp). SP. Brasil. santosg@unicamp.br 
40 anos quando o conheci, Enrico sabia exatamente quando ia aposentar-se e o pecúlio que teria. (Sennett, 2001, p. 14).

Certamente, iniciamos o século XXI sem as mesmas linearidades, perspectivas e previsibilidades de Enrico e Flávia, citados na epígrafe acima. As mudanças no mundo do trabalho, decorrentes principalmente da globalização e da reestruturação produtiva, têm colocado constantes desafios à sociedade capitalista, sobretudo para os países de economia menos dinâmica.

Na América Latina, por exemplo, devido à vulnerabilidade econômica e à necessidade de renegociação da exorbitante dívida externa, sua inserção no processo de globalização do capital tem-se dado de forma subordinada e dirigida por uma série de idéias impostas pelo Consenso de Washington ${ }^{1}$.

As teses deletérias que embasaram este Consenso têm ocasionado a redefinição do papel dos Estados nacionais sobre os processos econômicos, políticos e sociais; a privatização de empresas públicas lucrativas; a liberalização dos fluxos de investimento estrangeiro; a ampla desregulamentação da economia; a proteção da propriedade privada, etc. Portanto, constata-se, mais intensamente nos países dessa região, uma severa desestruturação no mercado de trabalho mediante o crescimento do desemprego estrutural, o afrouxamento de direitos sociais, as novas formas de contratação e de gerenciamento da força de trabalho - via flexibilização, precarização e terceirização, fragmentando a classe trabalhadora.

Desse modo, considerando o desemprego tanto um fenômeno inerente ao processo de acumulação capitalista como uma das consequiências das opções políticas governamentais, este artigo pretende discorrer sobre o seu papel na definição das atuais estratégias de avanço do capitalismo, bem como refletir sobre o processo de desestruturação do mercado de trabalho brasileiro e sua pequena inflexão nos anos mais recentes.

Abordamos inicialmente os tipos de desemprego a partir de alguns dados quantitativos que demonstram sua existência mais concreta e, em seguida, procuramos ressaltar que o desemprego é só uma face do processo de desestruturação do mercado de trabalho, que, na verdade, conta com a perversa flexibilidade, informalidade e precariedade dos postos de trabalho. E, por fim, analisamos brevemente o momento de uma ligeira melhora nos indicadores do mercado de trabalho no início dos anos 2000 .

1. OWashington consensus é uma expressão criada pelo economista John Williamson do Institute for International Economics (IIE), que expressa as proposiçōes da comunidade financeira internacional - especialmente o FMl e o BIRD - de ajuste das economias dos países periféricos às novas exigências dos países centrais. Suas diretrizes estão voltadas para a liberalização do comércio e dos investimentos, para as privatizaçōes e para a redução do orçamento público, com a focalização das políticas sociais e a venda de ativos estatais. 


\section{O significado do desemprego}

Há algumas décadas, conforme observaçôes de Mészáros (2002), o desemprego, mesmo em países de capitalismo avançado, estava reservado a áreas de pobreza e de subdesenvolvimento, levando as pessoas por ele afetadas para o completo esquecimento e descaso, na medida em que não havia preocupações com as repercussões socioeconômicas desse fenômeno. No entanto, como resultado das transformações capitalistas, o problema do desemprego, salienta o autor:

não mais se restringe à difícil situação dos trabalhadores nãoqualificados, mas atinge também um grande número de trabalhadores "altamente qualificados", que agora disputam, somando-se ao estoque anterior de desempregados, os escassos - e cada vez mais raros - empregos disponíveis. Da mesma forma, a tendência da amputação "racionalizadora” não está mais limitada aos "ramos periféricos de uma indústria obsoleta", mas abarca alguns dos mais "desenvolvidos" e modernizados setores da produção da indústria naval à acronáutica, e da indústria mecânica à tecnologia espacial (Mészáros, 2002, p. 1005).

De acordo com o relatório da Organização Internacional do Trabalho (OIT) - Tendências Mundiais do Emprego em 2007 -, o número de desempregados no mundo alcançou o recorde de 195,2 milhōes em 2006, mantendo inalterada a taxa de 6,3\% verificada em $2005^{2}$. Observa-se, portanto, que o crescimento do desemprego está cada vez mais no cotidiano da sociedade e com características mais complexas e heterogêneas, atingindo praticamente todos os segmentos sociais, embora apresentando em sua composição uma substancial desigualdade, ao considerar as variáveis de rendimento familiar, de idade, de gênero, de etnia e de escolaridade.

Tal estudo destaca que as mulheres não têm as mesmas oportunidades de emprego que os homens, estando 48,9\% delas trabalhando junto com $74 \%$ dos homens. Pior ainda é a situação dos jovens com idade entre 15 e 24 anos, onde 86,3 milhões (44\%) estão desempregados no mundo.

Várias são as análises que tentam identificar as causas desse fenômeno e que terminam por classificar alguns tipos de desemprego, levando-nos à reflexão do que seria o desemprego em nossa realidade brasileira.

Não poderíamos simplesmente considerar que a introdução de tecnologias mais sofisticadas seria a responsável pela redução dos empregos (desemprego

2. Disponível: http://www.agenciabrasil.gov.br/noticias/2007/01/24materia2007-0 I24.7259937 | 44Niew. Acesso em 02 de agosto de 2007. 
tecnológico) $)^{3}$, uma vez que esse mecanismo poupador de força de trabalho já acompanha a história do capitalismo desde seus primórdios. O primeiro a atentar para esse tipo de desemprego foi David Ricardo (1772-1823), por meio do livro Principios de Economia Politica e Tributação, publicado no início do século XIX, no contexto da Primeira Revolução Industrial na Inglaterra.

O cerne do processo de racionalização produtiva poupador de força de trabalho está em produzir mais com um menor número de trabalhadores, mantendo praticamente inalterado o tempo da jornada de trabalho, mediante a incorporação de inovações tanto tecnológicas como organizacionais. Todavia, o avanço tecnológico também está associado à criação de novos produtos, serviços e mercado, o que sugere a expansão de novos postos de trabalho ou a transferência de pessoal para outros ramos periféricos de apoio à produção.

O desemprego também não poderia ser tomado como consequiência de uma decisão voluntária do trabalhador, segundo a qual naturalmente ele passaria de um emprego a outro, permanecendo um tempo à procura de trabalho, o que se constituiria em um desemprego friccional ou flutuante. Essa ocorrência relaciona-se ao desequilíbrio entre a oferta e a procura de trabalho - os empregadores com vagas não identificam a existência de trabalhadores desocupados e os desempregados desconhecem as ofertas reais de trabalho.

Tampouco o desemprego pode ser descrito como conjuntural ou ciclico, em que há oferta de trabalho disponível aos salários em vigor, porém não há aproveitamento.

Essas são categorias mais apropriadas aos países capitalistas de economia mais avançada, pois as desigualdades no acesso ao posto de trabalho não se revelam tão intensas. Nos países de economia menos dinâmica presencia-se um aspecto mais crônico do que cíclico no fenômeno do desemprego, resultante do próprio modelo de desenvolvimento e caracterizado por ser um desemprego estrutural.

De acordo com Pochmann (2001), o estabelecimento de novos rumos para a economia brasileira desde 1990 tem consolidado um modelo solidário com o desemprego: revisão do papel do Estado na economia (racionalização e descentralização do gasto e privatização do setor público estatal); desregulação financeira (endividamento externo e maior dependência de ingressos financeiros) e econômica (fusão de grandes empresas produtivas e financeiras); estabilização monetária associada à maior oferta dos produtos importados e ao ingresso de recursos externos; reinserção externa mediante elevadas taxas de juros que têm atraído mais significativamente as aplicaçôes financeiras especulativas do que os investimentos produtivos.

3. Sobre os diferentes tipos de desemprego pesquisar em Cattani e Holzmann (2006). 
Nesse contexto, a probabilidade de lograr um emprego passa a resultar da conexão entre diferentes elementos: o perfil do desempregado (sexo, idade, escolaridade, etc.); as trajetórias ocupacionais, haja vista que as experiências anteriores de emprego tornam-se essenciais; as redes sociais constituídas nessas experiências ou na família; bem como o tipo de apoio institucional (seguro-desemprego, programas de intermediação, previdência social, etc.) destinado aos desempregados. Ou seja, a possibilidade de alcançar uma atividade profissional depende não só das características biográficas do trabalhador, mas igualmente da situação sócio-político-econômica de cada país e do amparo oferecido aos desempregados. No Brasil, a ligação entre esses elementos mostra-se muito mais complexa, posto que em nenhum momento de nossa história se implantou efetivamente um sistema de welfare público na proteção do trabalho.

Tem-se, portanto, que, se por um lado o desemprego pode ser analisado como uma consequiência inevitável da produção capitalista, que tende a substituir trabalho vivo por trabalho morto (desemprego tecnológico), por outro lado, entende-se que modelo de avanço tecnológico escolhido - poupador de força de trabalho - é um elemento basilar desse quadro caótico de desocupação, que é também fruto de decisões políticas.

Nesse contexto, o desemprego pode se constituir em uma variável estratégica de dominação do capital, na medida em que o aumento da oferta e a diminuição da procura por força de trabalho têm um impacto direto na regulação dos salários e no potencial de negociação da classe trabalhadora, que se torna cada vez mais fragilizada e submetida às regras do mercado.

O desemprego, assim, coloca-se como um problema social que causa instabilidade e um sentimento de insegurança generalizado em trabalhadores de todos os ramos e setores de atividade. Para Castel (1999), sua característica mais perturbadora é o reaparecimento de "trabalhadores sem trabalho", que ocupam na sociedade um lugar de supranumerários, de "inúteis para o mundo". Como Forrester (1997, p.10) sintetiza: "não é o desemprego em si que é nefasto, mas o sofrimento que ele gera [...]".

A ameaça de desemprego já causa sentimentos de vergonha, rejeição, abandono, insegurança, angústia e ansiedade que adentram o cotidiano dos indivíduos, configurando uma sociedade marcada pela indiferença, pela desconfiança e pela falta de compromisso mútuo entre as pessoas, que passam a buscar soluçōes individuais para problemas produzidos socialmente.

Para Baumann (2005), a experiência do desemprego indica a condição de sem-teto social, correspondendo à perda da auto-estima e do propósito da vida. "Desemprego", na verdade, revela uma condição temporária e anormal, de natureza transitória, que não mais condiz com a sociedade capitalista atual. Conforme o autor, os trabalhadores desempregados das geraçôes anteriores tornaram-se, na sociedade pós-1970, trabalhadores redundantes. 
Ser "redundante" significa ser extranumerário, desnecessário, sem uso-quaisquer que sejam os usos e necessidades responsáveis pelo estabelecimento dos padróes de utilidade e de indispensabilidade. [...] Ser declarado redundante significa ter sido dispensado pelo fato de ser dispensável - tal como a garrafa de plástico vazia e não-retornável [...]. "Redundância" compartilha o espaço semântico de "rejeitos", "dejetos", "restos", "lixo"com refugo. O destino dos desempregados, do "exército de reserva da mão-de-obra", era serem chamados de volta ao serviço ativo. O destino do refugo é o depósito de dejetos, o monte de lixo. (Bauman, 2005, p. 20).

Acompanhando o desemprego e todos os sofrimentos que ele provoca, temos, ainda, a redução dos salários, a precarização das condições e das relações de trabalho, com o aumento de práticas trabalhistas flexíveis, sem estabilidades nem garantias sociais.

\section{Informalidade e precariedade do mercado de trabalho}

De acordo com um estudo do Instituto de Pesquisa Econômica Aplicada (Ipea), publicado no livro Brasil: o Estado de uma Nação (Tafner, 2006), um dos efeitos colaterais do Plano Real foi a consolidação do mercado informal de trabalho na economia brasileira. Até 1995, a cada aumento na oferta de emprego formal correspondia uma redução do índice de trabalhadores na informalidade. Porém, a lógica mudou e a tendência mostra que a criação de novos empregos com carteira assinada não causa mais esse impacto. A informalidade passou a ser um traço característico do mercado de trabalho brasileiro, sobretudo nos últimos 11 anos.

Desse modo, amplia-se o excedente estrutural da força de trabalho e, assim, as novas formas de ocupação têm absorvido grande parte da população excluída do mercado formal, por meio de diversas estratégias de sobrevivência, incluindo: práticas de contrabando, pirataria, prostituição, tráfico de drogas, assaltos, sequiestros e outros crimes, presentes no que hoje se poderia chamar de "mercado ilegal de trabalho", estabelecendo uma linha muito tênue entre informalidade e ilegalidade.

Contudo, importa notar que a informalidade já se fazia presente no Brasil antes dos anos de 1990. Segundo Noronha (2001), a abordagem denominada de "velha informalidade" classificava frequientemente o trabalho informal, do período de 1960/1970, como subemprego. Buscava explicar o mercado de uma economia em transição, que começava a gerar uma massa de desempregados, os quais rapidamente se aglomeravam nas cidades industrializadas, recémvindos do campo. Nos fins da década de 1980, os direitos do trabalho foram 
reforçados pela nova Constituição e, simultaneamente, intensificou-se o comércio internacional; assim a abordagem "neoclássica", para o autor, culpa o excesso de regulação desse período pela expansão da informalidade. Já a "nova informalidade" resultaria, conforme Noronha (2001), das mudanças nos processos de trabalho, das novas concepçôes gerenciais e organizacionais e dos novos tipos de trabalho, os quais não exigem tempo nem locais fixos. Ou seja, trata-se de uma informalidade derivada da nova dinâmica econômica.

A intensificação desse processo decorre, principalmente, das formas de redução de custos adotadas pelas empresas, em virtude do acirramento da competitividade promovida principalmente pela entrada de produtos importados no País. As empresas, para ampliar seus espaços produtivos e sua margem de lucro adotaram novas alternativas que afetam diretamente os empregados. Demitem centenas de trabalhadores, terceirizam outros e recontratam alguns com remuneração bem inferior, inviabilizando a criação de empregos regulares e regulamentados. Convém também lembrar que as grandes empresas adotaram uma nova conduta de desnacionalização, fusão e incorporação, com intuito de tornarem-se mais competitivas.

As novas estratégias empresariais de produtividade e competitividade seriam um dos principais fatores explicativos das mudanças na composição ocupacional dos trabalhadores, que passam a vigorar, sobretudo, dentro de redes de terceirização e subcontratação. Estas redes estabelecem uma relação de complementaridade entre as grandes empresas e as de menor porte (micro, pequenas e médias). Estas fornecem para as primeiras vários tipos de insumos, produtos intermediários, embalagens e, inclusive, força de trabalho.

A força de trabalho terceirizada no País já corresponde a um terço das vagas criadas nas empresas privadas. Dos 6,9 milhôes de postos de trabalho abertos pelo setor privado de 1995 até 2005, 2,3 milhôes foram ocupados por terceirizados - que executam uma função numa empresa, mas recebem salário por outra. Em 1995 havia 1,8 milhôes de terceirizados formais. Dez anos depois, eram 4,1 milhões - uma expansão de $127 \% 0^{4}$.

Antes restrita às atividades não diretamente ligadas à produção (limpeza, vigilância, alimentação e segurança), a força de trabalho terceirizada expandese para os mais diversos setores (telefonia, automobilístico, eletroeletrônico, supermercados) e áreas (como telemarketing). Até o departamento de Recursos Humanos, considerado o "coração" de uma empresa, está atualmente nas mãos de terceirizados. A Philips, que chegou a possuir cerca de 20 mil funcionários no final da década de 1980, por exemplo, emprega hoje 6.000 funcionários e con-

4. Levantamento feito pelo Centro de Estudos Sindicais e de Economia do Trabalho (Cesit Unicamp), com informaçōes da Relação Anual de Informaçōes Sociais (RAIS) e do Cadastro Geral de Empregados e Desempregados (CAGED). (Folha de São Paulo, 2006). 
trata os serviços de mais 5.000 pessoas. No setor automobilístico, a Fiat empregou 25 mil trabalhadores nos anos 1980, porém, 26 anos depois, é considerada uma das empresas mais enxutas do setor; tem 9.000 funcionários diretos e 7.000 indiretos (prestadores de serviço e fornecedores) em Betim (MG). Em conflito com os trabalhadores em maio/2006, quando anunciou seu plano de reestruturação no País, a Volkswagen planejou cortar custos com medidas que também incluíam a terceirização de alguns setores da unidade de São Bernardo (SP). No País, a VW emprega de forma direta 21,5 mil pessoas em cinco fábricas e utiliza força de trabalho indireta de pelo menos 5 mil trabalhadores 5 .

Entretanto, apesar de os indicadores do mercado de trabalho revelarem que os maus resultados dos anos 1990 pouco se modificaram, alguns especialistas sugerem ter havido uma inflexão nos desempenhos da economia, no sentido de recomposição do mercado de trabalho, especialmente a partir de 2003 (Cesit, 2006).

Os primeiros anos do século XXI têm contrariado a visão fatalística da década anterior sobre o desaparecimento do mercado de trabalho formal. Segundo Dedecca e Rosandiski (2006), entre 1995 e 1998 foram criados 752 mil postos de trabalho, contra 4,5 milhões entre 2002 e 2004.

Houve, enfim, uma recuperação da atividade econômica, na qual se presencia que a informalidade tem crescido num ritmo menor que a elevação do emprego formal. No entanto, é preciso salientar que os postos de trabalho criados no governo atual são aqueles de baixa remuneração. Ou seja, mesmo o emprego formal crescendo, o que é bastante positivo, grande parte das vagas abertas foram com remuneração de até 02 salários mínimos mensais (Pochmann, 2006).

O mais importante é acreditar que, embora ainda não tenha sido possível uma recomposição significativa do mercado de trabalho, é admissível que esse quadro de desemprego e precarização realmente se reverta em condiçóes mais dignas de trabalho. Para tanto, é necessário que a sociedade pressione e o governo insista num ritmo de crescimento econômico sistemático acima de 5\% ao ano, acompanhado de um outro padrão de políticas públicas, para além do aspecto emergencial.

Certamente assistimos a alguns avanços no sentido da diminuição das desigualdades sociais; é plausível que estejamos no caminho certo, mas ainda não atingimos a velocidade necessária, marchamos a passos lentos.

A partir de dados da Pesquisa Nacional por Amostra a Domicílio (PNAD), pode-se constatar inicialmente que para o período de 1995 a 2006 houve uma diminuição substancial na quantidade de pobres no Brasil. Com destaque para as regiōes Centro-Oeste (37\%) e Sul (35\%) e em menor grau no Norte $(7,1 \%)$. O Nordeste teve queda de $17,2 \%$, tenha sido inferior ao desempenho do Su-

5. Conforme nota anterior. 
deste $(22,9 \%)$ (Corrêa et al., 2007).

Paradoxalmente, as regiōes onde houve as menores reduçôes nos números de pobres são exatamente onde se concentra a execução de importantes programas governamentais de transferência de renda. É provável, portanto, que a redução da pobreza não se efetive apenas com transferência de uma renda mínima aos mais pobres, mas, sobretudo, em função de um crescimento econômico consistente, que proporcione a apropriação de parcela desse incremento pelos pobres.

Nesse sentido, observamos, de acordo com o Atlas da exclusão social (Pochmann, M.; Amorim, R., 2003), que mais fortemente nas regiôes Norte e Nordeste do Brasil se manifesta uma "velha" exclusão social, fruto das lacunas deixadas pelo sistema de trabalho escravagista - do qual o Brasil foi o último a se libertar -, e pela falta das reformas clássicas (agrária, tributária e social) do capitalismo contemporâneo. Já as regiôes Centro-Sul, consideradas "acampamentos" de inclusão social, abrigam formas mais sofisticadas de exclusão, herdadas do modelo econômico imposto a partir de 1990, que gerou milhôes de desempregados escolarizados e famílias monoparentais que vivem na pobreza por ausência de renda. Esse seria o resumo do caleidoscópio da exclusão hoje no Brasil - ilhas de excelência e inclusão ao meio de verdadeiras prisões sociais.

As políticas de "(des)ajuste" desenvolvidas geram inúmeras novas formas de exclusão, na proporção em que agravam e precarizam as condições de trabalho e aumentam de modo exorbitante o número de desempregados. Parte considerável dos estratos médios urbanos da sociedade ficou mais vulnerável aos efeitos destas políticas, passando por um processo de deterioração da qualidade de vida. Logo, aos problemas da desigualdade social, da distribuição de renda e de pobreza somam-se as novas situaçôes de vulnerabilidade, gerando o que se está designando de "nova pobreza".

Não é mais possível, portanto, mantermos as análises socioeconômicas em velhas dicotomias - mercado formal e informal, pobres e ricos -, seja pela deterioração salarial, pela degradação dos serviços públicos ou pelo desemprego em larga escala. "A face moderna da pobreza aparece registrada no empobrecimento dos trabalhadores urbanos integrados nos centros dinâmicos da economia do país." (Telles, 2006, p 83).

\section{Considerações finais}

Em geral, dois são os fatores fundamentais gerados pela economia do País, que nos permitem compreender o grau de pobreza e de desigualdade vivido pela população brasileira hoje - a baixa qualidade e a quantidade de emprego. Desde meados dos anos 1990, convivemos com a expectativa da retomada do 
crescimento e da geração de empregos que, embora possam apresentar-se em um momento positivo, têm resultados ainda aquém do necessário.

O baixo crescimento econômico da última década do século passado, aliado à liberalização comercial-financeira, à racionalização e modernização da produção refletiu no nível de emprego e afetou os setores mais estruturados e organizados da economia. Portanto, ocorreu a redução da criação de novos postos no mercado de trabalho e o aumento considerável do desemprego e de outras formas de trabalho temporário, parcial, precário, terceirizado, subcontratado, relacionado à economia não formal e ao setor de serviços.

No início dos anos 2000, o mercado de trabalho brasileiro presenciou uma leve recuperação, com base em um aumento razoável da ocupação não agrícola, destacando-se a maior formalização do emprego, incentivada também por um melhor posicionamento do Estado com relação ao cumprimento das leis trabalhistas (Baltar; Krein; Moretto, 2006).

Entretanto, como nos esclarece Maia (2007), essa ligeira melhora da economia brasileira não atenuou de forma expressiva os elevados índices de precariedade do mercado de trabalho brasileiro. Na primeira metade dos anos 2000, conforme o autor, o emprego cresceu em ritmo mais acelerado que o da população economicamente ativa, e a taxa de desemprego caiu de $12,7 \%$ para $11,5 \%$. A população desempregada continua, contudo, representando parcela relevante da população economicamente ativa (11,4 milhões de pessoas em 2006), tendo ainda aumentado em 1,3 milhôes de pessoas seu contingente entre os anos 1999 e 2006. Além disso, cresceu em ritmo mais acelerado o número de desempregados com período de procura superior a 1 semana e daqueles à procura do primeiro emprego. Por outro lado, reduziu-se suavemente o tempo de desemprego, o que indica uma pequena melhora na probabilidade de aqueles que já trabalharam encontrarem uma nova posição no mercado de trabalho.

Assim, conclui-se que a melhora dos indicadores de desemprego no País foi incapaz de reverter a situação extrema de exclusão de uma parcela importante da população. Logo, faz-se necessária uma avaliação mais rigorosa do desenvolvimento das diversas políticas públicas em curso, no sentido de demarcar os pontos mais críticos, corrigir eventuais enganos e avançar nos acertos com relação a uma efetiva recomposição do mercado de trabalho brasileiro.

\section{Referências bibliográficas}

BALTAR, P.; KREIN, J. D.; MORETTO, A. O emprego formal nos anos recentes. Carta Sociale do Trabalho, Campinas: Unicamp. IE. Centro de Estudos de Economia Sindical e do Trabalho (CESIT), n.3, 2006. Disponível em: http://www.eco.unicamp.br/cesit/boletim/ Versao_Integral7.pdf 
BAUMAN, Zygmunt. Vidas desperdiçadas. Tradução de Carlos Alberto Medeiros. Rio de Janeiro: Jorge Zahar, 2005.

CASTEL, R. As metamorfoses da questão social. Petrópolis: Vozes, 1999.

CATTANI, Antonio D.; HOLZMANN, Lorena (Org.). Dicionário de trabalho e tecnologia. Porto Alegre: UFRGS, 2006.

CESIT. Carta Sociale do Trabalho, tendências recentes do emprego, n.3, jan.- abr./2006.

CORREAA, Marcio; MANSO, Carlos; BARRETO, Flávio; SIQUEIRA, Marcelo. Relatório sintético sobre a evolução dos indicadores de pobreza e desigualdade no Ceará. Fortaleza, 25 set. 2007 (Mimco).

DEDECCA, Claudio S.; ROSANDISKI, Eliane N. Enfim, esperança de réquiem para a tese da "inempregalidade". Carta Sociale do Trabalho, Campinas: Unicamp. IE. Centro de Estudos de Economia Sindical e do Trabalho, n. 3,2006. Disponível em: http:/www.eco.unicamp.br/ cesit/boletim/Versao_Integral7.pdf

FOLHA DE SÃO PAULO. Empregos terceirizados crescem $127 \%$ em dez anos. S.P., 28/08/ 2006. Disponível em: http://www1.folha.uol.com.br/fsp/dinheiro/fi2808200602.htm Acesso: 19 de set. 06.

FORRESTER, Viviane. O horroreconômico. São Paulo: Ed. Unesp, 1997.

MAIA, Alexandre G. Perfil do desemprego no Brasil nos anos 2000. Carta Sociale do Trabalho, Campinas: Unicamp. IE. Centro de Estudos de Economia Sindical e do Trabalho, n. 6, maio/ ago. 2007.

MÉSZÁROS, István. Para além do capital. São Paulo: Boitempo, 2002.

NORONHA, Eduardo G. Informal, ilegal, injusto: percepçóes do mercado de trabalho no Brasil. In: ENCONTRO ANUAL DA ANPOCS, 25., 2001. Caxambu, MG., 2001.

POCHMANN, Marcio. O emprego na globalização: a nova divisão internacional do trabalho e os caminhos que o Brasil escolheu. São Paulo: Boitempo, 2001.

POCHMANN, Marcio. A batalha pelo primeiro emprego. São Paulo: Publisher Brasil, 2000.

POCHMANN, Marcio; AMORIM, Ricardo (Orgs.). Atlas da exclusão social no Brasil.v.1. São Paulo: Cortez, 2003.

POCHMANN, Marcio; AMORIM, Ricardo (Orgs.). Qualidade das ocupaçôes no Brasil. Carta Sociale do Trabalho, Campinas: Unicamp. IE. Centro de Estudos de Economia Sindical e do Trabalho, n. 3, 2006.

SENNETT, Richard. A corrosão do caráter consequiências pessoais do trabalho no novo capitalismo. Rio de Janeiro: Ed. Record, 2001.

TAFNER, Paulo. Brasil: o Estado de uma nação. Brasília: Ipea, 2006.

TELLES, Vera. Direitos humanos: afinal do que se trata? Belo Horizonte:UFMG, 2006.

Recebido em 10 de abril de 2007 e aprovado em 28 de março de 2008. 